37.

8) F. Kayser, and M. Cohen, Metal Prog., '61 (1952) No: 6,79

9) K. A. Osipov, Sta] [N. S.] 4 (1944), 223., Chem. Abst. 39 (1945) 4848

10) E. Houdremont, H. Schrader, Kruppsche
Monatschefte, 13 (1932), 1

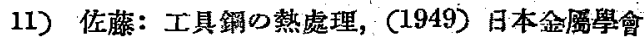

12) N. T. Guptsov; K. M. Gelfand, Bull. acad. sci., U.S.S. R., Classe. sci. tech (1947), 93 Ohem. Abst., 41 (1947) 583a

\title{
鐵錭中水素分析法の改善
}

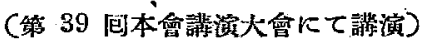

\author{
安田洋

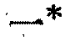 \\ IMPROVEMEN'T IN ANALYTICAL METHOD OF \\ HYDROGEN IN IRON AND STEEL
}

\section{Yoichi Yasuda}

Synopsis:

Analytical method of hydrogen in iron and steel was accomplished in chiefly by GakushinProcess, but in particulars it have to be improved. The authors studied the method of sampling from molten steel as well as treatment and analysis of the cast samples and concluded as follows. (1) Hydrogen contained in molten steel was very diffusible. Therefore, the cast sample must be analysed immediately after sampling or with the gas which captured in the glass-bell by mercury at roorn temperature

2) Scales of the cast sample combined with bydrogen in steels when analysing, and then the analytical value was decreased. So the scales of sample must bo grounded off.:

3) As hydrogen in steel was extracted in the form of methane, it must be analysed. For this purpose, it was convinient and exact that the volume of the residual oxygene was determined by addition of electrolytic hydrogen and then by its explosion.

\section{I. 緒 言}

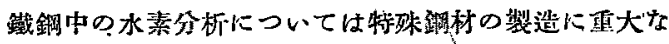

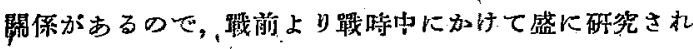

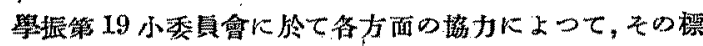

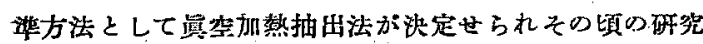

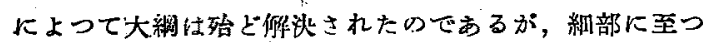
ては份研究改善望する點がある．學振法決定以後水素 分析に關して本邦で行われた主な磔等を拾つて見ると末 尾の交献の 1) 7に示す如くである，此等の研凂を通

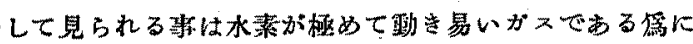
分析される染に沃の三段階に分つて陚料から分離される ので，此れをそれぞれに於て如何に正确に把尉するかと

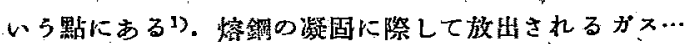

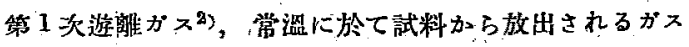
…第 2 次遊離がス ${ }^{3}$ ，高溫宾空中で抽出されるガス…第 了次遊崔がス。

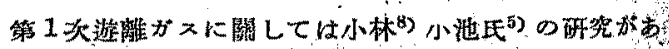

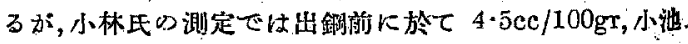
氏の測定では $0.05 \sim 0.3 \mathrm{cc} / 100 \mathrm{gr}$ ，となつて帴值的には

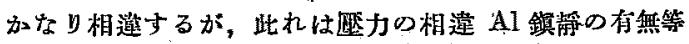

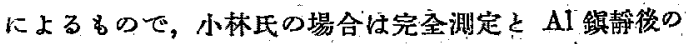
测定結果の一敉する事放されて居り，小池氏のデータ

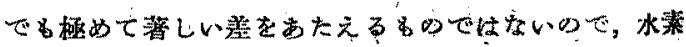

* 新理研:工業株式會社 
下關する限り，第1次遊離ガスはその澌定方法の困難と

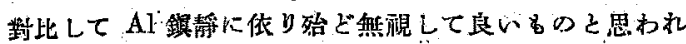

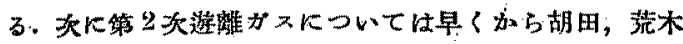
氏等の研笁があるが，此の显は極めて大きいのでト分の 注意を要する，第 3 次遊蜼ガスについては抽出法には殆

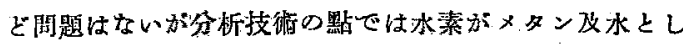
て抽出さ机た場合の取报について闍題があり，宗宮氏”，

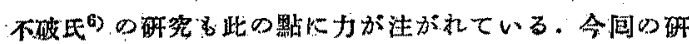

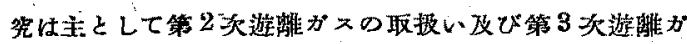
スの分析技衔の改善に關するすのだる。

\section{II. 第 2 次遊離カス}

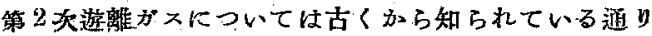

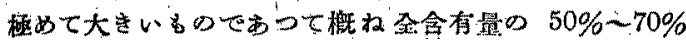
に洼する．第1圖はその放出狀況，笩工表はその放出率

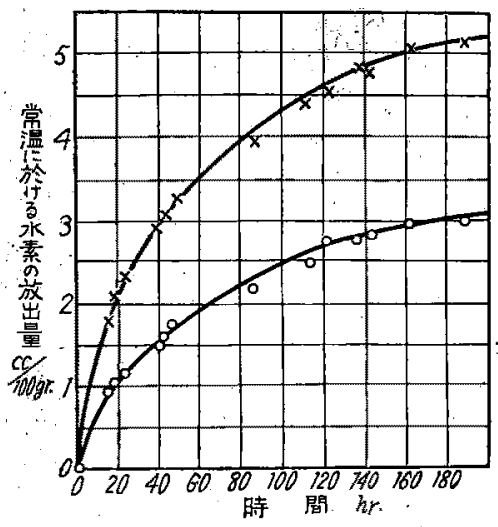

第1圆常溫に於ける水素放出爿況

第1表 常溫に於ける水素放出率

\begin{tabular}{|c|c|c|c|c|c|c|c|}
\hline 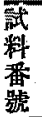 & $\begin{array}{l}\text { 試料 } \\
\text { 重量 }\end{array}$ & 常泪 & $\begin{array}{l}\text { 高 溫 } \\
\text { 敎出量 }\end{array}$ & $\begin{array}{l}\text { 全水 } \\
\text { 素量 }\end{array}$ & 水 表 & $\mid$ & 借，㤗 \\
\hline 1 & $47 \cdot 0 \mathrm{II}$ & $\mid \begin{array}{r}\mathrm{cc} \\
1.26\end{array}$ & $0 \cdot 66^{c c}$ & $\begin{array}{r}\mathrm{cc} \\
1.92\end{array}$ & $\begin{array}{l}c c / g r \\
4.08\end{array}$ & $\begin{array}{c}\% \\
65 \cdot 6\end{array}$ & \multirow{8}{*}{$\begin{array}{l}\text { 胡时氏 } \\
\text { 测 定 } \\
\text { 筧木 } \\
\text { 测 }\end{array}$} \\
\hline 2 & $53 \cdot 02$ & $1 \cdot 37$ & 0.83 & $2 \cdot 20$ & $4 \cdot 1 A$ & $62 \cdot 3$ & \\
\hline 3 & $54 \cdot 16$ & $2 \cdot 07$ & 0.93 & $3 \cdot 00$ & $5 \cdot 54$ & $69 \cdot 0$ & \\
\hline 4 & $48 \cdot 98$ & $2 \cdot 30$ & 0.64 & $2 \cdot 94$ & $6 \cdot 03$ & $78 \cdot 2$ & \\
\hline 5 & $44: 98$ & 0.72 & 0.76 & $1 \cdot 48$ & $3 \cdot 39$ & $48 \cdot 6$ & \\
\hline 6 & $193 \cdot 0$ & $5 \cdot 20$ & $6 \cdot 67$ & $11 \cdot 81$ & $6 \cdot 12$ & $77 \cdot 9$ & \\
\hline 7 & $39 \cdot 0$ & $1 \cdot 97$ & $1 \cdot 12$ & $3 \cdot 01$ & $7 \cdot 89$ & $64 \cdot 0$ & \\
\hline 8 & $60 \cdot 0$ & $2 \cdot 34$ & $1 \cdot 19$ & $3 \cdot 54$ & $5 \cdot 83$ & $66 \cdot 0$ & \\
\hline
\end{tabular}

を示するので一部を除き何れる著者の测定によるるので ある.第2次遊部がスについて著者改び從來の砸奖結果

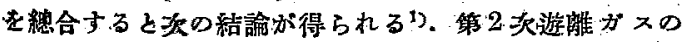

大部分約 $98 \%$ は $\mathrm{H}_{2}$ で他は $\mathrm{CO}$ 又は $\mathrm{N}_{2}$ である2). 第さ

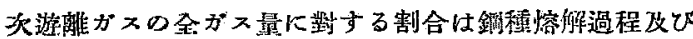

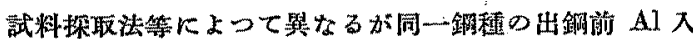
の試料にあつて略一定している核であるから鴙2次遊離 ガスのみの測定によつて全水素量をほ倠测する事が出

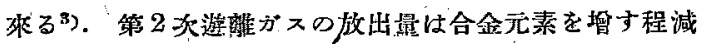

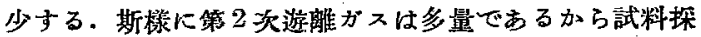

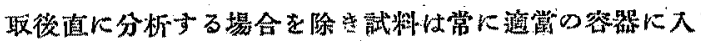
れて保存し第 2 次遊離がスを据捉して分析を行引必裂が

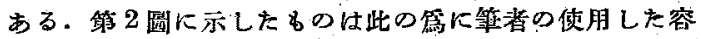
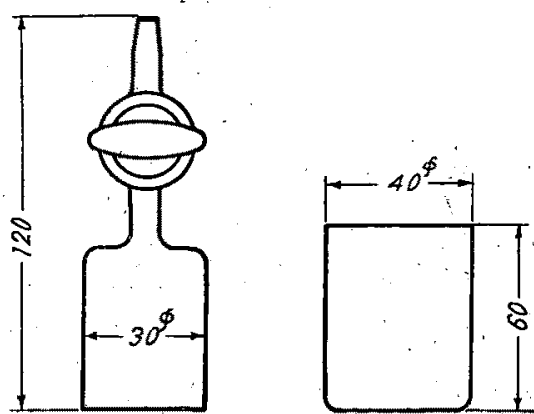

第 2 圆 水素分都試翻保存用水銀镜 (單位 $\mathrm{mm}$ )

器であつて熔銅の水素分析については加」る保存法を筫 施せ好限り普通の場合は結果は㱠ど信用すべからざるも。 のと考えて良い，何此の容器を用いる場合には學振型の

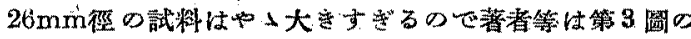
如き徑 $15 \mathrm{~mm}$ 試粼を用いた。斯栐な保存を行つた場合

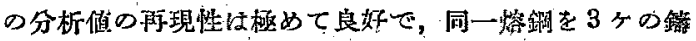
型に注いで作つた試料についての結果を第 2 表に示す.

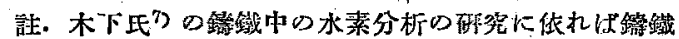

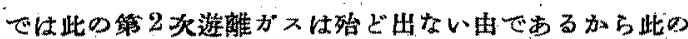
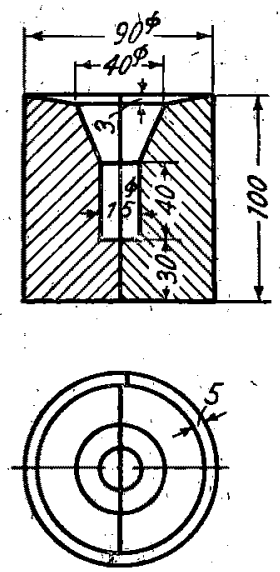

第3 圆 水琴分析試料探取朋鏌型 (單位 $\mathrm{mm}$ ) 
場合には保存容器め必畒は無いであろら。

第 2 表 分析値の再现性

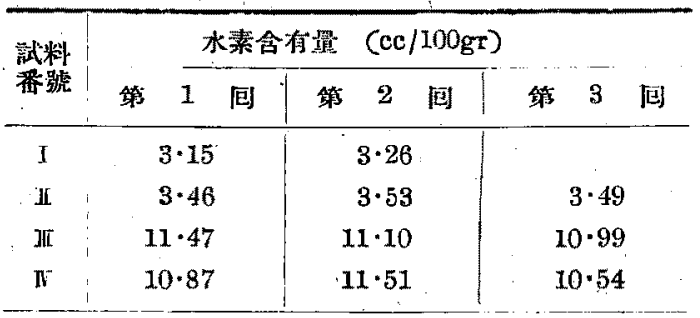

\section{III. 試料表面酸化膜の問題}

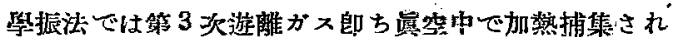
るがスの分析には，オルザットがス分析装镇を使用して いるので水分の分析は困離である。然るに水素蛙熱抽 出される際酸化物と反應して水となる加ら酸化物の存枉

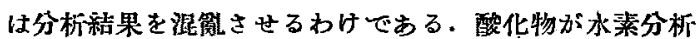

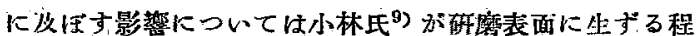
成微酸化物の影譬を調查し，普通のォルザットによる

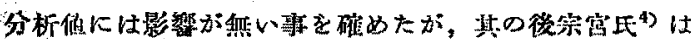
重乩法によつて此の水分を測定した結果此の程度の酸化

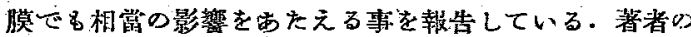

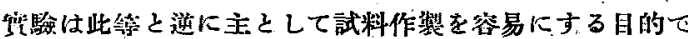

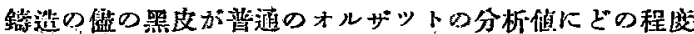
の影響を與えるかを調査したるのであるが，第３表に示

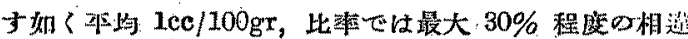

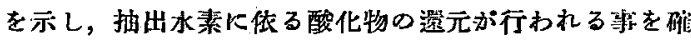
車に證明し試料は少くをるぺーパー00 程度に研确すべ きごある和が分つた。

\section{第3 表 水素分析に改任す試料表面㫮皮の影響}

\begin{tabular}{|c|c|c|c|}
\hline \multirow{2}{*}{ 試料窟號 } & \multicolumn{2}{|c|}{ 水素合有量 $(\mathrm{cc} / 100 \mathrm{gr})$} & \multirow{2}{*}{$\mathrm{B} / \mathrm{A}(\%)$} \\
\hline & 黑皮除去C & 垚皮体 (B) & \\
\hline 1 & $3 \cdot 29$ & $2 \cdot 29$ & 70 \\
\hline 2 & $5 \cdot 10$ & $4 \cdot 40$ & 86 \\
\hline 3 & $4 \cdot 82$ & $4 \cdot 68$ & 97 \\
\hline 4 & $4 \cdot 98$ & $4 \cdot 09$ & 81 \\
\hline 5 & $5 \cdot 20$ & $3 \cdot 90$ & 75 \\
\hline
\end{tabular}

\section{IV. メタンの分析}

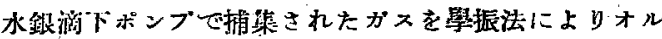
ザットで分析する場合，求めら礼た $\mathrm{H}_{2}, \mathrm{CO}, \mathrm{CO}_{2}, \mathrm{~N}_{2}$ 等

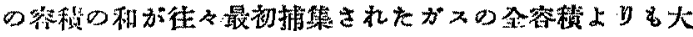

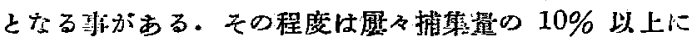

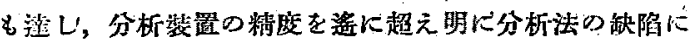

基くものである。此の原因は從來から加䓡抽出の祭，CO

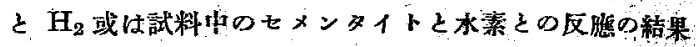

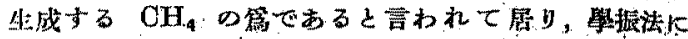

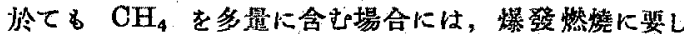
た酸装量を測定して $\mathrm{CH}_{4}$ の量を算出し，此の中の水

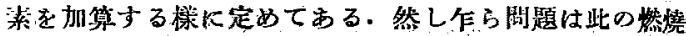
に翼された酸素を如何にして測定するがとい5點にあう

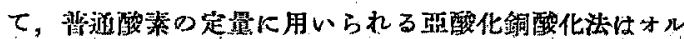

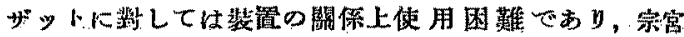
氏文はアルカり性ビロガロール溶液を用いているが，此 の方法は砝素吸收が正磪に行かれ始ので微量の $\mathrm{CH}_{4}$ œ

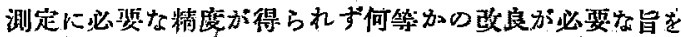
逃へている. 文 $\mathrm{H}_{2}, \mathrm{CO}$ 及 $\mathrm{CH}_{4}$ の混合ガスを分析す

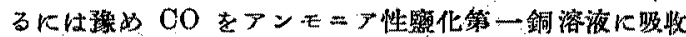
せしめて後 $\mathrm{H}_{2}$ そ $\mathrm{CH}_{4}$ を爆發法で定量する事る出來る

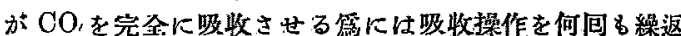

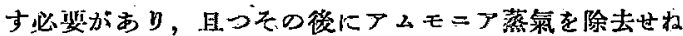

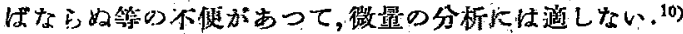
そこで著者は晋诹の爆發法で $\mathrm{CO}_{2}$ を颔收させた後，此

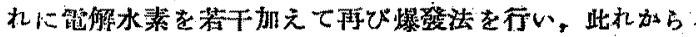
始め心燃㷪に費された $\mathrm{O}_{2}$ を求める方法考案した：第

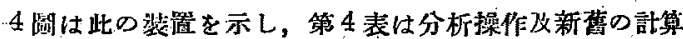
法を示す。

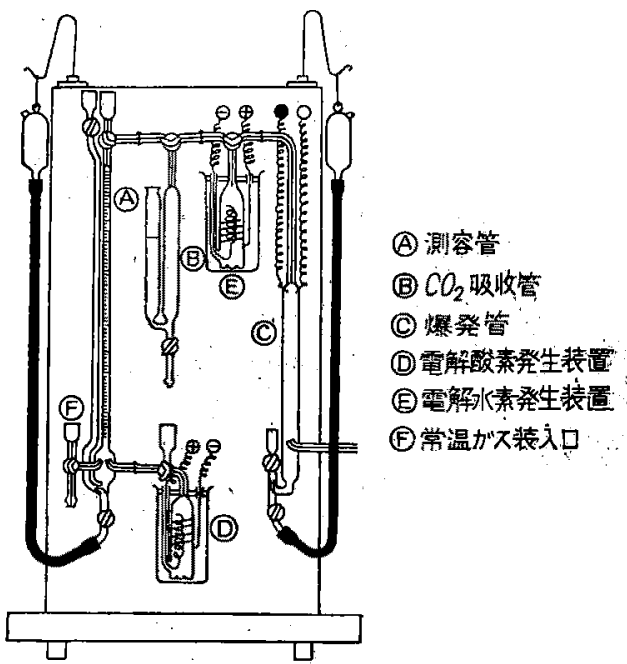

第 4 圆 メタン定量を合むがス分析辈置

$\mathrm{CO}, \mathrm{HI}_{2}, \mathrm{CH}_{4}, \mathrm{~N}_{2}$ の計算式忙狄の如くして得られる。

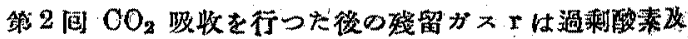

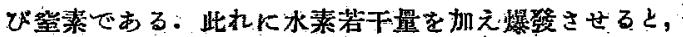

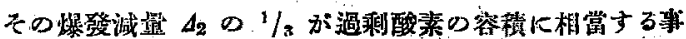




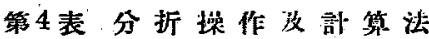

\begin{tabular}{|c|c|c|c|}
\hline 分析操作 & 定 & 淔 & 計 算 法 \\
\hline 排 搃 & 수교룔 & $\mathbf{T}$ & $\mathrm{CO}_{2}: \mathrm{C}=\mathrm{C}_{1}$ \\
\hline$-\mathrm{CO}_{2}$ & 第 1 炭酸ガス昌 & $\mathrm{C}_{1}$ & $\mathrm{H}_{2}: \mathrm{h}=A_{1}+\Delta_{2} /^{3}-\mathrm{a}$ \\
\hline $\mathrm{CO}_{9}$ & 添加酸素量 & a & $\mathrm{CH}_{4}: \mathrm{m}=1 / \mathrm{s}\left(3 \mathrm{a}-\Delta_{1}-\Delta_{2}-\mathrm{O}_{2}\right)$ \\
\hline 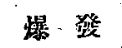 & 第 1 爆發減量 & $\Delta_{1}$ & $\mathrm{CO}: \mathrm{p}=1 / 3\left(A_{1}+\Delta_{2}+4 \mathrm{C}_{2}-3 \mathrm{a}\right)$ \\
\hline$-\mathrm{CO}_{2}$ & 第 2 岁酸ガス量 & $\mathrm{C}_{2}$ & $=\dot{\mathrm{C}}_{2}-\mathrm{m}$ \\
\hline & 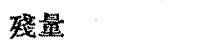 & $\mathbf{r}$ & $\Gamma_{2}: \mathrm{n}=\mathrm{r}-\left.\Delta_{2}\right|^{3}$ \\
\hline$+\mathrm{H}_{2}$ & . & & 銅中水素含有䭪 $[\mathrm{H}]={ }_{1} / 3\left(A_{1}+3 \mathrm{a}-A_{2}-2 \mathrm{C}_{2}\right) 100 \mathrm{k} / \mathrm{g}(\mathrm{cc} / 100 \mathrm{gr})$ \\
\hline 爆 發 & 第 2 爆發減量 & $A_{3}$ & 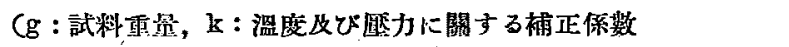 \\
\hline
\end{tabular}

第 5 表 新舊雨分析法による水素分析䊅果の比較

\begin{tabular}{|c|c|c|c|c|c|}
\hline 試 糊 & 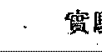 & & 鹤 計 筧 法 & 新 計 箱 法 & 簡 僻 法 \\
\hline $\begin{array}{c}\text { 需 解 琙 } \\
6 \cdot 92 \mathrm{gr}\end{array}$ & 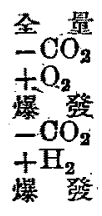 & $\begin{array}{l}5 \cdot 66 \mathrm{cc} \\
5 \cdot 60 \\
9 \cdot 80 \\
1 \cdot 58 \\
1 \cdot 16 \\
4 \cdot 35 \\
0 \cdot 93\end{array}$ & $\begin{array}{c}\mathrm{CO}_{2}=0.06 \mathrm{cc} \\
\mathrm{CO}=0.42 \\
\mathrm{H}_{2}=5 \cdot 34 \\
\quad \vdots \mathrm{H} \cdot 5 \cdot 82 \\
\text { 計 } \quad 54 \cdot 1 \quad \mathrm{cc} / 100 \mathrm{gr}\end{array}$ & $\begin{array}{l}\mathrm{CO}_{2}=0.06 \mathrm{cc} \\
\mathrm{OO}=0.24 \\
\mathrm{CH}_{4}=0.18 \\
\mathbf{H}_{2}=5 \cdot 16 \\
\mathbb{N}_{2}=0.02 \\
\text { 計 } 5 \cdot 66 \\
{[\mathrm{H}]=86 \cdot 9 \cdot \mathrm{co} / 100 \mathrm{gr}}\end{array}$ & 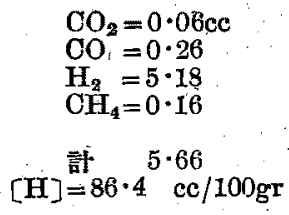 \\
\hline 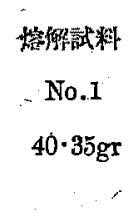 & 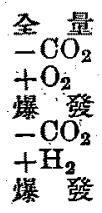 & $\begin{array}{l}1 \cdot 56 \\
1 \cdot 50 \\
3 \cdot 40 \\
1 \cdot 18 \\
0 \cdot 99 \\
3 \cdot 95 \\
1 \cdot 00\end{array}$ & $\begin{array}{c}\mathrm{CO}_{2}=0.06 \mathrm{cc} \\
\mathrm{CO}=0.19 \\
\mathrm{H}_{2}=1.42 \\
\\
{[\mathrm{H}]^{\text {討 }}=\mathbf{1 . 6 7}}\end{array}$ & 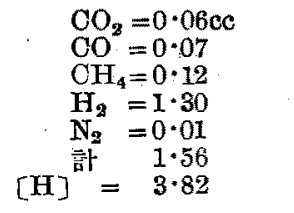 & $\begin{array}{c}\mathrm{CO}_{2}=0.06 \mathrm{cc} \\
\mathrm{CO}=0.18 \\
\mathrm{H}_{2}=1.31 \\
\mathrm{CH}_{\mathbf{3}}=0.11 \\
{\left[\mathrm{H}^{\text {計 }}=\mathbf{1 . 5 6}\right.} \\
\mathbf{3} \cdot 82\end{array}$ \\
\hline $\begin{array}{c}\text { 橴解式料 } \\
\text { No.2 } \\
44.65\end{array}$ & 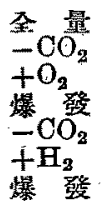 & $\begin{array}{l}0 \cdot 98 \\
0 \cdot 91 \\
2 \cdot 53 \\
1 \cdot 29 \\
1 \cdot 08 \\
4 \cdot 19 \\
1 \cdot 03\end{array}$ & $\begin{array}{c}\mathrm{CO}_{2}=0.07 \mathrm{cc} \\
\mathrm{CO}=0.21 \\
\mathrm{H}_{2}=0.76 \\
\\
{[\mathrm{H}]^{\text {計 }}=1.04} \\
1.70\end{array}$ & $\begin{aligned} & \mathrm{CO}_{2}=0.07 \mathrm{cc} \\
& \mathrm{CO}^{\prime}=0.12 \\
& \mathrm{CH}_{4}=0.09 \\
& \mathbf{H}_{2}=0.67 \\
& \mathbf{N}_{2}=0.03 \\
& \text { 計 } 0.98 \\
& {[\mathrm{H}]^{2}=1.90 }\end{aligned}$ & $\begin{array}{c}\mathrm{CO}_{2}=0.07 \mathrm{cc} \\
\mathrm{CO}^{2}=0.18 \\
\mathrm{H}_{2}=0.70 \\
\mathrm{CH}_{4}=0.06 \\
\\
{[\mathrm{H}]^{\text {訁ो }}=0.98} \\
\end{array}$ \\
\hline
\end{tabular}

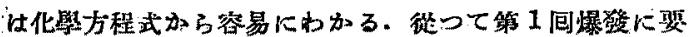

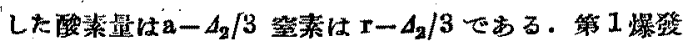

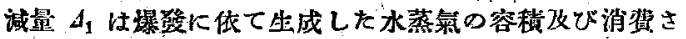
れた酸素の容䡩の和であり第 $2 \mathrm{CO}_{2}$ 量 $\mathrm{C}_{2}$ は $\mathrm{CO}$.及び $\mathrm{CH}_{4}$ の燃燒に体て生じた $\mathrm{CO}_{2}$ の昷である。此等の關倸 加ら次の速立方程式が得られ，これを解いて $\mathrm{h}, \mathrm{m}, \mathrm{p}$ が 求めら机る。

$$
A_{1}=3 \mathrm{~h} / 2+\mathrm{p} / 2+2 \mathrm{~m} \cdots(1) \quad \mathrm{C}_{2}=\mathrm{p}+\mathrm{m} \cdots(2) \quad \mathrm{a}-
$$
$\Delta_{2} / 3=\mathrm{p} / 2+\mathrm{h} / 2+2 \mathrm{~m} \cdots(3)$ 又此の方法に上る結果と算 來の方法の結果の比䡸の一例を第 5 表に示す. 表に示さ

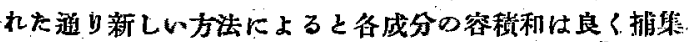

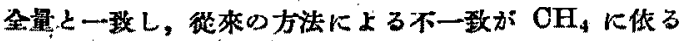

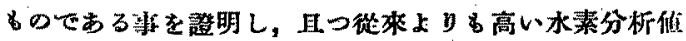
を與える.但し第 5 表に示した訣算法では捕莱したガス の中には酸素は合まれていないと假定している.箬し酸

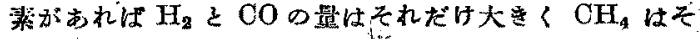
だけ少なく出るから，水素の分析值として酸素の量だけ 少なく觀湘される翋でする。捕集がス中に酸素が含まれ

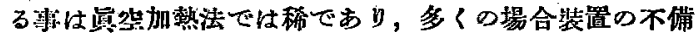
から来るのであるが，此れが斯梾な誤差を與えるから注

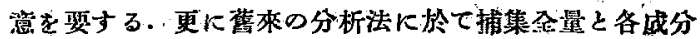

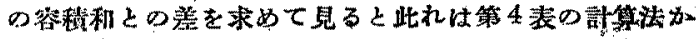

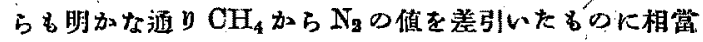
するわけであり，第 5 表の惯例に於てむ3例其に正磪に 一敘している－罢案加熱抽出法で得られる捕集ガス中に $\mathrm{N}_{2}$ の含まれる事は， $\mathrm{O}_{2}$ の場合と同じく比较的少量です

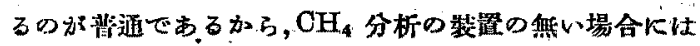

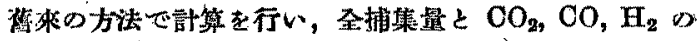
客皘利との美を来め此れを $\mathrm{OH}_{4}$ として㭪正を行えば $\mathrm{N}_{2}$

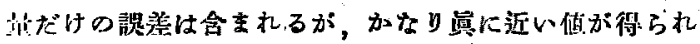


る、第 5 表に於て簡缏法として記したのは此の方法によ る゙优である. $\mathrm{CH}_{4}$ の量は普通すまり大きくないが, 試

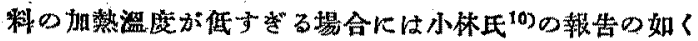
次式の反㗹が進行し $\mathrm{CH}_{4}$ の生成が促進されその昷が暂 大する. $\mathrm{Fe}_{3} \mathrm{O}+2 \mathrm{H}_{2} \rightleftarrows 3 \mathrm{Fe}+\mathrm{OH}_{4}\left(\log \mathrm{K}=\log \mathrm{P}_{\mathrm{H}_{2}}{ }^{2}\right)$ $\left.\mathbf{P}_{\mathrm{CH} 4}=7990 / \mathrm{T}+8 \cdot 75\right)$ 著者は試料加熱螅として最初シ リット㡾を用いていたがその後此れを゙クロム橴に變え 大所 $\mathrm{CH}_{\mathbf{4}}$ の生成が大となり第 5 表の例の如く含有水素

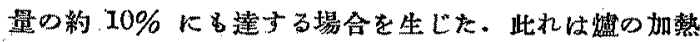

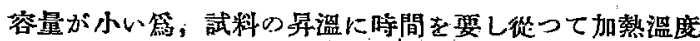
を低くしたのを同榢の繥果を來たしたものる思われる。

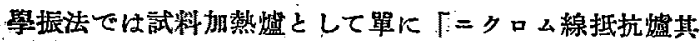

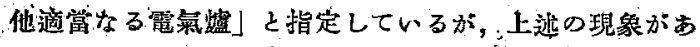
るので，加熱容量が大きく界溫速度の大をいるのを橴ぶ 必装がある。

\section{V. 結 論}

本研究に於て得られた結諭は次心如くだある.1〉䗆䬼 儿含有される水素は試料採取㷋常溫心於て極めて放出

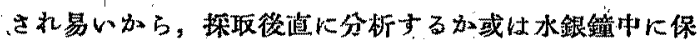
存し逸出するガスを捕集して併せて分析する事加必ず必

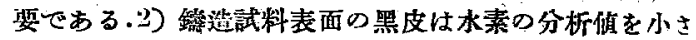
(するから除去の必要がある.3〉加整法で捕集されるが

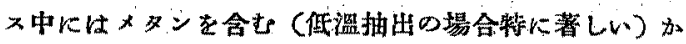
ら此れを定量する必娎がある。此れを定最するには殘的

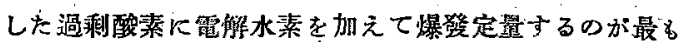
簡易正確である：倍水上して出て來る水素については宗

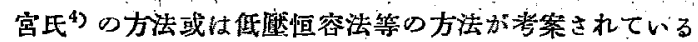
が未だ簡易にして萲用的といら所に至らず合後に残され

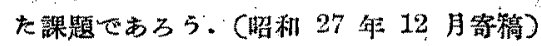

文献

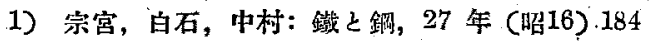

2) " " " : " " (") 203

3) " " " " $" \#$ (" $) 301$

4)" " " " 29 年 (昭18) 863

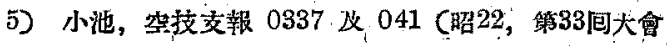
にて丵满)

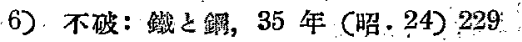

门 木下，原：昭 24 , 第 37 问大會にて講演

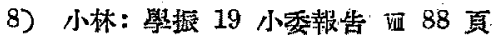

9 小林: 學振 19 小垠告 证 67 页

10) 小林：學㖘 19 小委報告 胹 66 頁 